\title{
Views and experiences of men who have sex with men on the ban on blood donation: a cross sectional survey with qualitative interviews
}

\author{
(a) (1) $\Theta$ OPEN ACCESS
}

\author{
P Grenfell research fellow ${ }^{1}$, W Nutland research consultant ${ }^{1}$, S McManus research director ${ }^{2}, \mathrm{~J}$ \\ Datta research fellow $\left.\right|^{1}, \mathrm{~K}$ Soldan epidemiologist ${ }^{3}$, $\mathrm{K}$ Wellings professor of sexual and reproductive \\ health $^{1}$
}

${ }^{1}$ Department of Social and Environmental Health Research, Faculty of Public Health and Policy, London School of Hygiene and Tropical Medicine, London WC1H 9SH, UK; ${ }^{2}$ National Centre for Social Research, London EC1V OAX; ${ }^{3}$ Health Protection Agency, London NW9 5EQ

\begin{abstract}
Objective To explore compliance with the UK blood services' criterion that excludes men who have had penetrative sex with a man from donating blood, and to assess the possible effects of revising this policy. Design A random location, cross sectional survey followed by qualitative interviews.

\section{Setting Britain.}

Participants 1028 of 32373 men in the general population reporting any male sexual contact completed the survey. Additional questions were asked of a general population sample $(n=3914)$. Thirty men who had had penetrative sex with a man participated in the qualitative interviews (19 who had complied with the blood services' exclusion criterion and 11 who had not complied).
\end{abstract}

Main outcome measure Compliance with the blood services' lifetime exclusion criterion for men who have had penetrative sex with a man.

Results $10.6 \%$ of men with experience of penetrative sex with a man reported having donated blood in Britain while ineligible under the exclusion criterion, and $2.5 \%$ had donated in the previous 12 months. Ineligible donation was less common among men who had had penetrative sex with a man recently (in previous 12 months) than among men for whom this last occurred longer ago. Reasons for non-compliance with the exclusion included self categorisation as low risk, discounting the sexual experience that barred donation, belief in the infallibility of blood screening, concerns about confidentiality, and misunderstanding or perceived inequity of the rule. Although blood donation was rarely viewed as a "right," potential donors were seen as entitled to a considered assessment of risk. A one year deferral since last male penetrative sex was considered by study participants to be generally feasible, equitable, and acceptable.

Conclusions A minority of men who have sex with men who are ineligible to donate blood under the current donor exclusion in Britain have nevertheless done so in the past 12 months. Many of the reasons identified for non-compliance seem amenable to intervention. A clearly rationalised and communicated one year donor deferral is likely to be welcomed by most men who have sex with men.

\section{Introduction}

In the 1980s blood services in many countries introduced measures to prevent HIV and other bloodborne viruses from entering the blood supply. ${ }^{12}$ Among these was a lifetime ban on donation by men who had ever had oral or anal sex with a man-such as the UK blood services' "MSM donor deferral" (which defined men who have sex with men (MSM) as only those who had engaged in oral or anal sex between men, a departure from the term's use in other contexts) — in contrast to a year long deferral for most other high risk groups. ${ }^{3}$ Several factors have prompted reconsideration of this rule. The number of heterosexually acquired cases of HIV infection has increased in some settings, ${ }^{4}$ and improvements in blood screening techniques have reduced the "window period" between infection and detection, reducing the risk of HIV infected donations entering the blood supply. ${ }^{56}$

The issue has attracted intense debate $e^{27-12}$ leading, in some countries, to legal challenges to the deferral. ${ }^{13}{ }^{14}$ Opponents argue that a lifetime ban on blood donation by men who have sex with men is discriminatory, infringes individual rights, is disproportionate to risk, and reduces the supply of available blood. ${ }^{9-12}$ Those who would retain the ban counter that the safety of the blood supply is paramount, that the lifetime ban is effective in helping to achieve this goal, and that a less stringent rule would be likely to increase the risk of transfusion-transmissible infections. ${ }^{715}$

In several countries the exclusion has been reduced to a specified time since last having penetrative sex with a man (six months in South Africa ${ }^{16} ; 12$ months in Australia, Sweden, Japan, 
Hungary, and Argentina ${ }^{17-19}$; and five years in New Zealand ${ }^{18}$ ). In Spain and Italy deferral criteria now apply to high risk sexual behaviours, removing any mention of partner gender. ${ }^{20}$ In the UK, Canada, and the US any man who has ever had oral or anal sex with another man (or since 1977 in North America), whether protected or unprotected, is permanently excluded from donating blood. $^{21} 22$

The study reported here was designed to explore compliance with the lifetime "MSM donor deferral" in Britain, to assess possible effects of a revision to the rule on compliance and willingness to donate, and to inform how best any revision might be formulated and communicated.

\section{Methods}

\section{Survey design and procedures}

Between April 2009 and June 2010, we conducted a population based survey, followed by qualitative interviews with male survey respondents reporting any sexual contact with a man. We recruited a household sample of men and women in Britain aged 18 and older via the TNS-BMRB Omnibus Face-to-Face survey. ${ }^{23}$ The Omnibus survey uses a two stage, random location sampling strategy in which age and gender stratified quota samples are drawn from randomly selected geographical districts of approximately 150 households. ${ }^{24} \mathrm{~A}$ core of sociodemographic questions is followed by bespoke modules of questions funded by other agencies. Verbal informed consent is sought from respondents in accordance with the ethical guidelines of the Market Research Society. ${ }^{25}$

We designed, piloted, and incorporated into the survey a 20 question module relating to blood donation, sexual practice, and sexual identity, in CASI (Computer-Assisted Self Interview) format. Male respondents were asked whether they had ever had sexual contact with a man, using a question derived from the National Survey of Sexual Attitudes and Lifestyles (Natsal). ${ }^{26}$ Men answering yes were asked about their experience of oral or anal (penetrative) sex with a man, age at first such occasion, self defined sexual identity, history of and most recent blood donation in Britain, donation since first penetrative sex with a man, disclosure of sex with men at last blood donation, reasons for non-disclosure, reasons for not donating blood, awareness of donor deferrals, and perceptions of current and potential revisions to the MSM donor deferral.

During the first two weeks of the survey, two questions about the perceived role of the UK blood services and the appropriateness of the lifetime MSM donor deferral were asked of the entire Omnibus sample (1813 men and 2101 women).

\section{Qualitative interview}

Men reporting any sexual contact with a man were asked if they would be willing to be re-contacted to take part in the qualitative component of the study. Among those agreeing and providing a contact telephone number, we included both men who had donated ineligibly under the MSM donor deferral and those who had not done so in our invitation to participate in an in depth interview. The survey identified "non-compliers" as men who had donated blood in Britain since their first experience of penetrative sex with a man and since the introduction of the UK MSM donor deferral in 1985, and identified "compliers" as men who had had penetrative sex with a man but who had not donated blood in Britain since 1985 or since their first experience of penetrative sex with a man (if this happened after 1985). These terms are used to reflect knowing and unknowing ineligible donation.
We invited all "non-compliers" who agreed to being re-contacted to interview and purposively selected "compliers" to reflect a range of demographic characteristics and to include men with and without experience of penetrative male sex in the past 12 months. We estimated that a survey sample of 1000 men reporting any male sexual experience would be required to identify a sufficient number of "non-compliers" willing to participate in the interview (based on estimates of the prevalence of same sex sexual experience and blood donation among men in Britain ${ }^{21}$ ).

At follow-up the confidential and anonymous nature of the research was stressed. Interviews were audio-recorded, with written informed consent, and took place in a venue and at a time of each participant's choice. We used a topic guide to explore experiences of and motivations for donating blood, including disclosure of sex with men; views on the MSM donor deferral criterion; suggestions for alternative MSM deferral criteria; likely impact of a revised criterion on donating practice and compliance; views on communicating a revised deferral; and sexual identity. Participants were given illustrative examples of countries with a five year MSM donor deferral (New Zealand), a one year deferral (Australia), and an exclusion criterion based on unprotected sex outside a regular sexual partnership within a defined time period (Spain). Interviews lasted on average 90 minutes.

Participants in the qualitative component were offered a $£ 20$ voucher in recognition of their contribution to the study, as well as contact information for the UK Blood Services and services offering support on sexual health and sexual identity.

\section{Data analysis \\ Survey data}

Compliance status was assessed from "age at first penetrative sex with a man," "current age," "year of last blood donation," and "interview week" (calculated compliance). Where data were unavailable or chronology was unclear, we used data on reported "donation since first penetrative sex with a man" and "year of last donation" (reported compliance). Concordance between calculated and reported compliance was high $(97 \%, \kappa=0.796$, $\mathrm{P}<0.001)$. We estimated the incidence of blood donation using "year of last donation" and "interview week" (see footnote to table $3 \Downarrow$ ).

Comparisons between sample subgroups were made with Pearson $\chi^{2}$ tests and Fisher's exact tests. Although these tests assume a simple random probability sample, the random location design is a good approximation of this. ${ }^{24}$ All analyses were performed using Stata 10 (Stata Corp, Texas).

\section{Qualitative data and integrated analyses}

Interviews were transcribed verbatim and anonymised. Data were managed using NVivo8 software (QSR International, 2008). Data were analysed iteratively and thematically across accounts. ${ }^{28}$ Transcripts were reviewed by multiple authors (PG, $\mathrm{WN}, \mathrm{KW}$ ) to agree on the meanings of emerging codes. Relations between themes were explored and key overarching thematic areas identified. Survey and qualitative findings were integrated at the interpretation stage to address the key research objectives and identify overarching meta-themes. ${ }^{29}{ }^{30}$ 


\section{Results \\ Characteristics of the sample}

Three per cent of men responding to the Omnibus survey (1028/32 373) reported having had any sexual contact with a man and were routed to the blood donation module of the questionnaire (figure $\Downarrow$ ). Their mean age was 41.8 years (SD 16.86). Compared with men reporting no such experience, they were younger, of higher socioeconomic status and educational level, and more commonly single (table $1 \Downarrow$ ). Five per cent of male Omnibus survey respondents (1634) did not answer the question on male sexual contact and, compared with those who did, were older ( $41 \% \vee 24 \%$ aged $\geq 65$ ), had lower socioeconomic status $(40 \% v 30 \%$ in the two lowest socioeconomic groups), had lower educational level (32\% v $20 \%$ had not completed secondary education), and were more commonly divorced, widowed, or separated (19\% v 11\%).

Just under half of men reporting male sexual experience (457/1028) agreed to be re-contacted. Eighty eight were selected for in depth interview, of whom 30 participated, 13 declined, and 45 could not be contacted (see figure $\downarrow$ ). The average age of participants in the qualitative interviews was 42 years (range 21-71 years). They represented a range of sociodemographic characteristics and included eight "non-compliers" with the MSM donor deferral, three possible "non-compliers" (the chronology of first penetrative sex with a man and last blood donation was unclear, but there was some indication that they had donated since becoming ineligible), and 19 "compliers." All (possible) "non-compliers," however, were aged $\geq 35$, had not donated blood in the past two years, and did not intend to do so again.

Almost half of male survey respondents reporting any same sex sexual contact had ever had penetrative sex with a man, just over half of whom (227/489) had done so in the previous 12 months and $23 \%$ of whom described their sexual identity as "straight" or heterosexual (table $2 \Downarrow$ ).

\section{Compliance with the lifetime MSM donor deferral}

Of the 474 male survey respondents who reported experience of male penetrative sex, $50(10.6 \%)$ had donated blood in Britain since becoming ineligible under the MSM donor deferral ("non-compliers") and 11 (2.5\%) had donated in the previous year (table $3 \Downarrow$ ). Ineligible donation was significantly less common among men who had had male penetrative sex recently (in the past 12 months) compared with those who had last done so longer ago (table 3 ), and among those who self identified as gay or homosexual compared with those who had not $(5.2 \% \mathrm{v}$ $15.5 \%, \mathrm{P}<0.001)$. There were no differences in age, socioeconomic status, education, country of residence, or ethnicity by compliance status (data not shown).

"Non-compliers" described their reasons for having donated blood ineligibly in the qualitative component. Some had discounted the blood services' exclusion based on risk on various grounds-that they practised safer sex or knew their own risk status, because of a belief in the infallibility of blood screening procedures, or because of feelings of resentment over the unfairness of the exclusion in the absence of an equivalent for heterosexual practices.

'I just said 'No' for that question ... for whether I'd had sex with men... I knew I shouldn't but I did because I knew for a fact that my blood was healthy; I didn't have HIV ... and I also know the fact that any sex that I did have I always took protection."- “"Non-complier," interview 13
Others had discounted the experience that barred them from donating blood. This was particularly the case for men whose experience of sex with men had happened far enough in the past or just once to be considered insignificant to current risk status. A non-consensual sexual experience was too distressing to recall at the time of blood donation.

"I answered 'No' [to the screening question asking about sex with a man].... I disowned it, um, because I was abused and raped.... It didn't happen as far as I was concerned at that time."- - Non-complier," interview 5

For some, there was a reluctance to assume an identity associated with sex between men. For those who were, at the time, not open about their sexual practices or identity, the need for discretion had deterred self deferral in a public setting:

“They didn't know about me [my sexuality] till I was 25 ... and we [father and son] worked together.... It would have

been very difficult to say to dad, 'No, I can't go and donate blood."'-_Non-complier," interview 20

A lack of clarity regarding the terms of the MSM donor deferral was also a barrier to compliance for some ineligible donors.

\section{Knowledge and awareness}

Survey findings revealed extensive lack of awareness of the rules relating to donation by men who had sex with men. Only one in four men with any experience of male sexual contact was aware that having had penetrative sex with another man barred donation. Almost a third believed that only unprotected penetrative male sex was a criterion for deferral. One in four did not know which groups were excluded (table $4 \Downarrow$ ). The proportion of "compliers" who cited having had any male sexual contact as their reason for not donating blood was almost as high as the proportion citing having had male penetrative sex (table $3 \Downarrow$ ).

A high degree of confidence was expressed in the certainty of medical science. Nearly half of all men with experience of male penetrative sex held that they would donate blood regardless of the rules because they believed the screening of blood to eliminate risk (table $4 \Downarrow$ ). This confidence in blood testing procedures was a common argument made by participants in the qualitative component against the lifetime MSM donor deferral. The possibility of administrative error resulting in the release of screened but infected blood was rarely mentioned and awareness of the "window period" between infection and detection, and its implications for screening effectiveness, was limited.

\section{Views on the existing lifetime MSM donor deferral}

Of the sample of 3914 men and women responding in the first two weeks of the Omnibus survey, most (1425 (78.6\%) men, $1672(79.6 \%)$ women) were of the view that the role of the blood services was to protect the blood supply rather than individual rights, agreeing with the statement: "The aim of the blood donation service is to make sure the country's blood supply is safe and free from infection, not to enable anyone who wants to to give blood." At the same time, a sizeable minority (38.5\% men and $43.5 \%$ women) saw the MSM donor deferral as inflexible and excessive, agreeing that: "The current ban on gay men seems too rigid; it doesn't make sense for a man who has had a single homosexual experience even before the HIV epidemic to be banned from being a blood donor."

Among men with experience of male sexual contact, less than half agreed that the lifetime ban should be retained to ensure 
blood safety, and this proportion was significantly lower among men with experience of male penetrative sex $(\mathrm{P}<0.001)$ (table $4 \Downarrow)$. Their views were further elaborated in the qualitative research. Although blood safety was recognised as the primary priority of the blood services, the ban was seen as outdated and founded more on the need for public reassurance than current scientific evidence. In view of the perceived absence of an equivalent deferral relating to high risk heterosexual practices, the MSM donor deferral was described as "unfair" and, by some, "discriminatory."

"There's a lot of ... STIs and HIV and everything in relationships that don't involve male-male sex so it's really discriminatory ... maybe it's the stereotype of guys that sleep around.... It's kind of offensive for me ... I've probably had less sexual encounters than most straight women or men."- “Complier," interview 6

The lack of transparency in the rationale for the exclusion was seen to undermine confidence in its scientific basis. The inclusion of oral and protected sex was considered by some as contrary to safer sex messages. Of widespread concern was the "blanket" nature of the ban and its failure to distinguish between lifestyles conferring different risk status.

"You have gay men, bisexual men, men who identify as heterosexual but have a bit of, you know, a dalliance every now and again, you have that whole range ... you have promiscuous people, monogamous people, celibate people. You can never have ... sexual behaviour as a homogenous group."-“Complier," interview 4

Qualitative interviews also revealed tensions between concern for the right of the individual to donate blood and the protection of public health. Although giving blood was rarely considered a right, there was a strong sense that all potential donors were entitled to a considered assessment of risk based on current scientific evidence. Some saw the blood services as failing to benefit from potential supplies of usable blood by excluding healthy donors.

\section{Views on revision of the MSM donor deferral}

An individual risk assessment approach, taking account of risk status and risk reduction practice, regardless of one's own or one's partner's gender, was widely considered to be the ideal replacement for the current MSM donor deferral.

"It [would] no longer discriminate against a group of people, it makes it more sensible in a way that if a man's had sex with 50 women then I think he's a lot more at risk than if another man's had sex with two men, kind of thing. So ...

it's fairer and more acceptable."-_Complier," interview 22

This option was, however, acknowledged to involve more in depth questioning that would be costly, complex, and a potential deterrent to the wider donor population. A one year MSM deferral (since last sex with a man) was viewed as a generally acceptable, equitable, and sufficiently cautious alternative.

"It's a step in the right direction and it would bring sex with men into the same category as other increased risky sexual behaviours."- "Complier," interview 4

A five year MSM deferral was typically dismissed as "tokenistic" and designed rather to appease gay and bisexual men than to take account of current epidemiological evidence. Such a revision was thought likely to have little impact on the number of eligible donors while retaining the potential to provoke negative public reaction. A one year deferral, on the other hand, was considered more scientifically sound, accounting conservatively for the window period for infections and any risk of men donating towards the latter part of a deferral period. Alignment with donor deferrals for most other high risk groups, and with other countries, was an important consideration for some, who felt that discrepancies undermined confidence in the current exclusion criteria.

"It should be consistent. The world ... is a smaller place. We all travel consistently ... you can't tell me the rules in one country should be different to the rules in another."- "Non-complier," interview 20

\section{Possible response to a revised criterion}

Roughly half of survey respondents with experience of male sexual contact held that a changed criterion would not affect their motivation to donate blood (table $4 \Downarrow$ ). There was no significant difference by compliance status. One in three felt they would be more likely to give blood under a revised criterion because the lifetime MSM donor deferral had served as a deterrent in the past. Roughly the same proportion saw themselves as more likely to donate under a revised rule because of newly conferred eligibility, and the proportion was significantly higher among current "compliers" than "non-compliers" ( $\mathrm{P}=0.030)$ (table $4 \Downarrow$ ).

These views were echoed in the qualitative research by men who were currently acting in accordance with the lifetime donor exclusion but who would become eligible under a revised criterion.

'I would give blood.... I don't have unprotected sex outside my relationship, I don't have unprotected sex inside my relationship, so ... I'd give blood, yeah.... My impression is that it would cause other gay men to give

blood."-“Complier," interview 25

Those who would remain ineligible foresaw little effect on their donating behaviour. Although most participants felt they would continue to comply with a revised donor deferral criterion, many were reluctant to speculate on other men's likely future compliance. Although some felt that a revised criterion may encourage donation towards the latter part of a deferral period-on the basis of perceived low risk to the blood supply - this was seen as avoidable by providing a clear rationale for the rule and taking this concern into account when setting deferral periods.

\section{Views on the communication and implementation of a revised criterion}

Less than half of survey respondents reporting male sexual contact considered the current donor deferral rules to be clear and easy to understand, and almost three quarters felt that more explanation was required regarding eligibility criteria (table $4 \Downarrow$ ). Clear and transparent communication of the rationale for deferral was considered essential by participants in the qualitative research, both to facilitate compliance and to reassure excluded groups that the criterion was founded on evidence rather than prejudice.

Confidentiality was seen as a vital issue. Concerns were raised regarding the reliability of self reported information on sexual behaviour in the semi-public setting of blood donation sessions. This issue was particularly salient for men who were not publicly open about their experience of sex with men.

"I wouldn't want my colleagues to know about stuff like that really, and they could quite easily look over your shoulder ... or if you tick the box and you were excluded, then they'd want to know why you couldn't give blood, so ... it's 
probably not the best place to do it ... on the day in the actual centre?"- "Non-complier," interview 9

An online screening questionnaire, which could be completed privately and submitted remotely in advance of donation sessions, was seen as a preferable means of ensuring anonymity. In terms of communication, participants favoured a broad advertising strategy combined with tailored information targeted at men identifying themselves as gay or bisexual, and potential donors. Generic messages were considered appropriate for mainstream advertising, while more targeted messages could make specific reference to sexual practices resulting in deferral. Web based resources were seen as an important source of additional information for those who remained unsure of their eligibility.

\section{Discussion}

\section{Summary of findings}

This is the first published study reporting experience of and views on blood donation deferral criteria in a general population sample of gay, bisexual, and other men who have had sex with men. Our data show a sizeable minority of men to have donated blood since having had penetrative sex with a man. In depth accounts suggest that this experience had often happened some considerable time in the past or on a single or rare occasion. Of smaller size, but of greater concern, was the proportion of men who had donated ineligibly in the previous year. Reasons for non-compliance included self categorisation as low risk, discounting the sexual experience that barred donation, need for discretion around sexual identity or practice, misconceptions relating to procedures safeguarding blood, misunderstanding of the exclusion criterion, and resentment over its perceived inequity. Awareness of the terms of the MSM donor deferral was disquietingly limited. The current lifetime exclusion was criticised by the men in our study, who saw it as inequitable, discriminatory, and, above all, lacking a clear rationale. Taking into account issues relating to feasibility, equity, and scientific coherence, a one year deferral since last male penetrative sex was seen as a preferable alternative. A five year MSM donor deferral was not considered acceptable, and the lack of support for this option does not augur well for implementation or compliance.

\section{Strengths and limitations}

Our study had a number of limitations. To obtain a sufficiently large population based sample of men with experience of male sexual contact cost effectively, we used a frequently repeated Omnibus survey with a random location design rather than a true random probability survey. This inevitably has the potential to introduce bias into the sample. The prevalence of reported male sexual experience in our study was considerably lower than that in the National Survey of Sexual Attitudes and Lifestyles in $2000(8.4 \%),{ }^{31}$ possibly reflecting differences in methodology and age range.

Differences in the characteristics of men who did or did not respond to the question regarding male sexual contact raise further concerns in this context, particularly if these characteristics are also associated with propensity to disclose sexual practice or comply with the donor deferral. The CASI format of the questionnaire is likely to have facilitated disclosure, but our estimates of non-compliance with the MSM donor deferral and of same sex experience among men should be treated with caution. Further, the inclusion in the qualitative sample of only past, and not current, "non-compliers" aged 35 years and older who were now acting in compliance with the MSM donor deferral meant that the voices of younger men and those who had donated ineligibly more recently were not heard. Nevertheless, our general population sample has advantages over convenience samples recruited from gay venues; notably, its capacity to capture the views and experiences of men who may not be publicly open about their sexual experience with men. Although the qualitative findings reflect a purposive sample of men and so cannot be generalised to the wider population of gay, bisexual, and other men who have sex with men, this mixed methods design allowed us to build on the findings of a population based survey to gain an in depth understanding of these men's experiences and views of the MSM donor deferral.

\section{Conclusions and policy implications}

The crucial question is what impact a revised MSM donor deferral criterion might have on compliance. Previous research investigating male donors' history of sex with men has been unable to capture the experiences of men who currently do not donate but who would become eligible under a less restrictive deferral. ${ }^{32} \mathrm{We}$ are not able to predict with certainty how donation behaviour may change under revised criteria. However, according to our data, men who would remain ineligible to donate under a one year MSM donor deferral were less likely to have ever not complied with the lifetime blood donation ban.

Encouragingly, many of the barriers to compliance identified in our study seem amenable to intervention. Our data suggest considerable scope for improving the clarity with which deferral criteria are communicated; the privacy afforded potential donors in disclosing sexual behaviours; and the adequacy of explanation for the rationale for donor deferrals, including the fallibility of blood screening. A crucial finding, that some "non-compliers" dissociated past male sexual experience from the MSM donor deferral, has important implications for communication of any deferral criterion. It is critical that health professionals consider the possibility that men who do not identify themselves as gay, bisexual, or "men who have sex with men" may not absorb health information targeted at these groups.

In Sweden, where rates of and reasons for non-compliance among gay and bisexual men are similar to those found in this study, ${ }^{33}$ blood safety is predicted to be optimal under a one year MSM deferral (compared with other deferral periods) on the basis of anticipated improved compliance. Early data from Australia comparing blood donations before and after the change from a five year MSM donor deferral to a one year deferral have shown no significant increase in the prevalence of HIV infected donations or the proportion of infected donors reporting sex with men, although the sample was small and the observation of more new infections in donors reporting sex with men needs further attention. ${ }^{18}$ Should a revision be made to the MSM donor deferral criterion in the UK, careful monitoring of its effects will be needed.

Replacing the lifetime MSM donor exclusion with one seen as fairer is likely to be welcomed by most gay, bisexual, and other men who have sex with men. Increased endorsement by the constituency in question might improve compliance rates, particularly among men who currently donate ineligibly owing to perceived discrimination. If the lifetime MSM donor deferral does indeed have the potential to reinforce public prejudice towards gay and bisexual men-a concern raised by opponents of the ban ${ }^{9-11}$ and echoed by men in this study-then a revised rule might go some way towards addressing the negative social 
attitudes that may deter men from disclosing sexual practices and complying with the deferral rule.

The findings of this study are intended to inform a review of UK blood donation policy with regard to men who have sex with men and to show the importance of consulting the constituent group before introducing changes to public health policy. Our findings are likely to be of value not only in the UK but in other countries considering changes to policy regarding blood donation by men who have sex with men.

We thank all study participants, including volunteers in the piloting phase; Sarah Shepherd and colleagues at TNS-BMRB Omnibus for survey fieldwork; Ben Armstrong for statistical advice; Rachael Parker for administrative support; the Terrence Higgins Trust for assistance in piloting the questionnaire; and the Terrence Higgins Trust, Stonewall, and the National AIDS Trust representatives for advice on dissemination. We also thank the Health Protection Agency for commissioning the project, Brian McClelland for initiating this research, Su Brailsford for commenting on the final study report, and the Department of Health for funding the study.

Contributors: KW led the study design, with contributions from SM, KS, and JD, and contributions to the development of data collection tools by $P G$ and WN. PG led the data collection and analysis, with contributions from WN, KS, JD, and SM. All authors contributed to data interpretation and revisions to the manuscript, the first draft of which was prepared by PG. All authors had full access to the data derived from the study and can take full responsibility for the integrity of the data and the accuracy of the data analyses. $\mathrm{KW}$ is guarantor for the study. Competing interests: All authors have completed the Unified Competing Interest form at www.icmje.org/coi_disclosure.pdf (available on request from the corresponding author) and declare that WN worked for Terrence Higgins Trust until 2009 and continues to undertake consultancy work for the organisation; KS is employed by the UK Health Protection Agency and is the budget holder for other funding received from the Department of Health for work unrelated to this submission. There is no personal or financial gain attached to this publication.

Ethical approval: The study was approved by the Southampton \& South West Hampshire Research Ethics Committee (reference No 09/H0504/99).

Funding: The Department of Health funded the study and had no involvement in study design, data collection, analysis, or the decision to submit for publication. The views expressed are not necessarily those of the Department of Health.

Data sharing: No additional data available.

1 Gunson HH, Rawlinson VI. HIV antibody screening of blood donations in the United Kingdom. Vox Sang 1988;54:34-8.

2 Hurley R. Bad blood: gay men and blood donation. BMJ 2009;338:b779.

3 The National Blood Service for England \& North Wales. Exclusion of men who have sex with men from blood donation: position statement. 2010. www.blood.co.uk/can-i-giveblood/exclusion/.

4 Health Protection Agency. HIV in the United Kingdom: 2009 report. HPA, 2009. www.hpa. org.uk/web/HPAweb\&HPAwebStandard/HPAweb_C/1259151891866.

5 Soldan K, Davison K, Dow B. Estimates of the frequency of HBV, HCV, and HIV infectious donations entering the blood supply in the United Kingdom, 1996 to 2003. Euro Surveill 2005;10:17-9.
6 Coste J, Reesink HW, Engelfriet CP, Laperche S, Brown S, Busch MP, et al. Implementation of donor screening for infectious agents transmitted by blood by nucleic acid technology: update to 2003. Vox Sang 2005;88:289-303.

7 Brooks JP. Should men who have ever had sex with men be allowed to give blood? No. BMJ 2009;338:b318.

8 Franklin IM. Is there a right to donate blood? Patient rights; donor responsibilities. Transfus Med 2007;17:161-8.

9 Galarneau C. Blood donation, deferral, and discrimination: FDA donor deferral policy for men who have sex with men. Am J Bioeth 2010;10:29-39.

10 Roehr B. Should men who have ever had sex with men be allowed to give blood? Yes. BMJ 2009;338:b311.

11 Tatchell P. End the gay blood ban. Guardian 2009 Nov 30. www.guardian.co.uk commentisfree/2009/nov/30/gay-sex-give-blood-ban.

12 Wainberg MA, Shuldiner T, Dahl K, Gilmore N. Reconsidering the lifetime deferral of blood donation by men who have sex with men. CMAJ 2010;182:1321-4.

13 Canadian Blood Services/Societe Canadienne du Sang v Freeman; 2010. www. bloodservices.ca/CentreApps/Internet/UW_V502_MainEngine.nsf/resources/ SafetyAndTesting/\$file/CanadianBloodServicesVFreeman2010-part1.pdf.

14 Tasmanian Anti-Discrimination Tribunal. Antidiscrimination decisions-Cain, Micheal v the Australian Red Cross Society. Hobart: Tasmanian magistrates court, 2009. www. magistratescourt.tas.gov.au/decisions/anti-discrimination_decisions/c/Cain_v_The Australian_Red_Cross_Society_2009_TASADT_03.

15 FDA Blood Products Advisory Committee. Transcript of 67th Meeting: Thursday, September 14, 2000. FDA, 2000. www.fda.gov/ohrms/dockets/ac/cber00.htm\#Blood\%20Products.

16 South African National Blood Service. Pre-donation tips. 2010. www.sanbs.org.za/ newdonors_preDon.htm.

17 Leiss W, Tyshenko M, Krewski D. Men having sex with men donor deferral risk assessment: an analysis using risk management principles. Transfus Med Rev 2008;22:35-57.

18 Seed CR, Kiely P, Law M, Keller AJ. No evidence of a significantly increased risk of transfusion-transmitted human immunodeficiency virus infection in Australia subsequent to implementing a 12-month deferral for men who have had sex with men. Transfusion 2010;50:2722-30.

19 Blodcentralerna (Swedish National Blood Service). Regler för Blodgivning (guidelines for blood donation). 2010. www.geblod.nu/general.aspx?Pageld=6.

20 Cruz Roja Española-Centro de Transfusion. La donacion de sangre. Quien puede donar sangre? 2010. www.donarsangre.org/donacion quien.htm\#.

21 National Blood Service for England \& North Wales. Who can't give blood? 2010. https:// secure.blood.co.uk/c11 cant.asp.

22 Martucci J. Negotiating exclusion: MSM, identity and blood policy in the age of AIDS. Social Studies of Science 2009;4:215-41

23 TNS Research International. BMRB Omnibus. 2010. www.tns-ri.co.uk/what-we-do/bmrbomnibus.aspx.

24 Orton S. Evidence of the efficiency of quota samples. Survey Methods Centre Newsletter 1994:15.

25 Market Research Society. The Data Protection Act 1998 \& market research: guidance for MRS members 2003. www.mrs.org.uk/standards/downloads/revised/legal/The $\%$ 20Data\%20Protection\%20Act\%201998\%20and\%20Market\%20Research.pdf.

26 Johnson AM, Mercer CH, Erens B, Copas AJ, McManus S, Wellings K, et al. Sexual behaviour in Britain: partnerships, practices, and HIV risk behaviours. Lancet 2001;358:1835-42.

27 McManus S. Exclusion of men who have had sex with men from blood donation. Sexuality in social work and social care conference, London 2006.

28 Silverman D. Doing qualitative research. Sage, 2000.

29 O'Cathain A, Murphy E, Nicholl J. Three techniques for integrating data in mixed methods studies. BMJ 2010;341:C4587.

30 Farmer T, Robinson K, Elliot SJ, Eyles J. Developing and implementing a triangulation protocol for qualitative health research. Qual Health Res 2006;16:377-94.

31 Mercer CH, Fenton KA, Copas AJ, Wellings K, Erens B, McManus S, et al. Increasing prevalence of male homosexual partnerships and practices in Britain 1990-2000: evidence from national probability surveys. AIDS 2004;18:1453-8.

32 Sanchez AM, Schreiber GB, Nass CC, Glynn S, Kessler D, Hirschler N, et al.. The impact of male-to-male sexual experience on risk profiles of blood donors. Transfusion 2005:45:404-13.

33 Socialstyrelsen (National Board of Health and Welfare, Sweden). Summary of analyses on selection criteria for blood donors and requirements for methods of testing. Unit for Communicable Disease Prevention and Control, 2009.

Accepted: 1 September 2011

\section{Cite this as: BMJ 2011;343:d5604}

This is an open-access article distributed under the terms of the Creative Commons Attribution Non-commercial License, which permits use, distribution, and reproduction in any medium, provided the original work is properly cited, the use is non commercial and is otherwise in compliance with the license. See: $\mathrm{http}: / /$ creativecommons.org/licenses/by$\mathrm{nc} / 2.0 /$ and http://creativecommons.org/licenses/by-nc/2.0/legalcode. 


\section{What is already known on this topic}

Several countries have revised their policy regarding blood donation by men who have sex with men (MSM) Improved blood screening techniques and epidemiological knowledge have prompted reconsideration of the lifetime MSM blood donor deferral in the UK

\section{What this study adds}

A one year donor deferral was preferred by men who have sex with men to the existing lifetime deferral in the UK on the basis of perceived rationality and equity

Improvements to communication and confidentiality, and a clear explanation of the rationale, will be essential for compliance with and acceptability of a revised MSM donor deferral criterion

\section{Tables}

Table 1| Sociodemographic characteristics of $32 \mathbf{3 7 3}$ men responding to the Omnibus survey, by experience of sex with men. Values are numbers (percentages) or respondents unless stated otherwise

\begin{tabular}{|c|c|c|c|c|c|c|}
\hline & \multicolumn{3}{|c|}{ Sexual contact with a man } & \multicolumn{3}{|c|}{ Penetrative sex with a man ${ }^{*}$} \\
\hline & No $(n=29711)$ & Yes $(n=1028)$ & $P$ value of difference & No $(n=522)$ & Yes $(n=489)$ & $P$ value of difference \\
\hline Age (years): & $(\mathrm{n}=29711)$ & $(n=1028)$ & & $(n=522)$ & $(\mathrm{n}=489)$ & \\
\hline $18-34$ & $8284(27.9)$ & $400(38.9)$ & $<0.001$ & $197(37.7)$ & $196(40.1)$ & $<0.001$ \\
\hline $35-49$ & 7391 (24.9) & $299(29.1)$ & & $123(23.6)$ & $171(35.0)$ & \\
\hline $50-64$ & $6759(22.8)$ & $208(20.2)$ & & $120(23.0)$ & $86(17.6)$ & \\
\hline$\geq 65$ & $7277(24.5)$ & $121(11.8)$ & & $82(15.7)$ & $36(7.4)$ & \\
\hline Marital status: & $(n=29706)$ & $(n=1028)$ & & $(n=522)$ & $(n=489)$ & \\
\hline Single & $7531(25.4)$ & $478(46.5)$ & $<0.001$ & $219(42.0)$ & $252(51.5)$ & $<0.001$ \\
\hline Married or in civil partnership & $15627(52.6)$ & $328(31.9)$ & & $210(40.2)$ & $113(23.1)$ & \\
\hline Living as a couple & $2977(10.0)$ & $142(13.8)$ & & $52(10.0)$ & $85(17.4)$ & \\
\hline Divorced, widowed, separated & $3571(12.0)$ & $80(7.8)$ & & $41(7.9)$ & $39(8.0)$ & \\
\hline Socioeconomic groupt: & $(n=29711)$ & $(n=1028)$ & & $(n=522)$ & $(\mathrm{n}=489)$ & \\
\hline $\mathrm{A}$ or $\mathrm{B}$ & $6209(20.9)$ & $281(27.3)$ & $<0.001$ & $140(26.8)$ & $134(27.4)$ & $<0.001$ \\
\hline $\mathrm{C} 1$ & $8021(27.0)$ & $300(29.2)$ & & $127(24.3)$ & $168(34.4)$ & \\
\hline $\mathrm{C} 2$ & $6538(22.0)$ & $159(15.5)$ & & $88(16.9)$ & $71(14.5)$ & \\
\hline $\mathrm{D}$ or $\mathrm{E}$ & $8943(30.1)$ & $288(28.0)$ & & $167(32.0)$ & $116(23.7)$ & \\
\hline Education: & $(n=29635)$ & $(n=1025)$ & & $(\mathrm{n}=522)$ & $(\mathrm{n}=489)$ & \\
\hline Incomplete primary or secondary & $5936(20.0)$ & $118(11.5)$ & $<0.001$ & $73(14.0)$ & $43(8.8)$ & 0.043 \\
\hline Complete secondary $\ddagger$ & $12669(42.8)$ & $421(41.1)$ & & $214(41.2)$ & $203(41.6)$ & \\
\hline Further qualification & $4877(16.5)$ & $176(17.2)$ & & $89(17.1)$ & $82(16.8)$ & \\
\hline Higher education (university) & $6153(20.7)$ & $310(30.2)$ & & $144(27.7)$ & $160(32.8)$ & \\
\hline Country of residence: & $(\mathrm{n}=29711)$ & $(n=1028)$ & & $(n=522)$ & $(\mathrm{n}=489)$ & \\
\hline England & $26521(89.3)$ & $936(91.1)$ & NS & $472(90.4)$ & $449(91.8)$ & NS \\
\hline Scotland & $2286(7.8)$ & $65(6.3)$ & & $35(6.7)$ & $28(5.7)$ & \\
\hline Wales & $904(3.0)$ & $27(2.6)$ & & $15(2.9)$ & $12(2.5)$ & \\
\hline Ethnicity: & $(n=29705)$ & $(n=1027)$ & & $(n=522)$ & $(\mathrm{n}=489)$ & \\
\hline White & $25187(84.8)$ & $914(89.0)$ & $<0.001$ & $454(87.1)$ & $443(90.6)$ & NS \\
\hline Mixed & $446(1.5)$ & $19(1.9)$ & & $10(1.9)$ & $9(1.8)$ & \\
\hline South Asian or Asian British & $2428(8.2)$ & $40(3.9)$ & & $26(5.0)$ & $14(2.9)$ & \\
\hline Black or black British & $957(3.2)$ & $24(2.3)$ & & $14(2.7)$ & $10(2.0)$ & \\
\hline Chinese or other & $687(2.3)$ & $30(2.9)$ & & $17(3.3)$ & $13(2.7)$ & \\
\hline
\end{tabular}

*Oral or anal sex.

†Classified according to social grade (produced by the Market Research Society).

$\ddagger$ Secondary education completed at 16 or 18 years of age. 
Table 2/ Sexual practice and identity among the 1028 men reporting any male sexual contact in the Omnibus survey in Britain. Values are numbers (percentages) of respondents

\begin{tabular}{|c|c|c|c|c|c|}
\hline & \multicolumn{3}{|c|}{ Experience of penetrative male sex } & \multirow{2}{*}{$\begin{array}{l}\text { Experience of non-penetrative } \\
\text { male sexual contact only }\end{array}$} & \multirow[b]{2}{*}{ All } \\
\hline & In past 12 months & Before past 12 months only & Any & & \\
\hline Survey respondents & $256(24.9)$ & $227(22.1)$ & $489(47.6)$ & $522(50.8)$ & $1028(100)$ \\
\hline Sexual identity: & $(n=254)$ & $(n=224)$ & $(n=484)$ & $(n=515)$ & $(n=1009)$ \\
\hline Homosexual or gay & $185(72.3)$ & $51(22.5)$ & $238(48.7)$ & $24(4.6)$ & $265(26.3)$ \\
\hline Bisexual & $50(19.5)$ & 65 (28.6) & $116(23.7)$ & $53(10.2)$ & $172(17.1)$ \\
\hline Heterosexual or straight & $15(5.9)$ & $95(41.9)$ & $113(23.1)$ & $411(78.7)$ & $528(52.3)$ \\
\hline Other, don't know & $4(1.6)$ & $13(5.7)$ & $17(3.5)$ & $27(5.2)$ & $32(4.4)$ \\
\hline
\end{tabular}




\begin{tabular}{|c|c|c|c|c|c|}
\hline \multirow{2}{*}{$\begin{array}{l}\text { Donation practice and } \\
\text { compliance with "MSM donor } \\
\text { deferral"* }\end{array}$} & \multicolumn{3}{|c|}{ Men with experience of male penetrative sex } & \multirow{2}{*}{$\begin{array}{l}\text { Men with experience } \\
\text { of non-penetrative } \\
\text { male sex only }\end{array}$} & \multirow[b]{2}{*}{ All } \\
\hline & In past 12 months & $\begin{array}{l}\text { Before past } 12 \text { months } \\
\text { only }\end{array}$ & Anyt & & \\
\hline Ever donated blood in Britain§ & 57/256 (22.3) & 69/227 (30.4) & $126 / 485(25.8)$ & $164 / 521(31.4)$ & 295/1006 (28.7) \\
\hline $\begin{array}{l}\text { Ever donated blood despite } \\
\text { ineligibility } 9\end{array}$ & $17 / 249(6.8)^{\star *}$ & $33 / 219(15.1)^{\star *}$ & $50 / 474(10.6)$ & - & - \\
\hline Donated in past 12 months $\dagger \dagger$ & $5 / 238(2.2)$ & 6/212 (2.8) & $11 / 456(2.5)$ & $16 / 475(3.3)$ & $27 / 946(2.9)$ \\
\hline 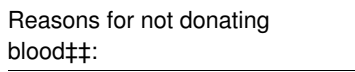 & $(n=190)$ & $(n=153)$ & $(n=348)$ & $(n=349)$ & $(n=707)$ \\
\hline $\begin{array}{l}\text { Excluded because of } \\
\text { penetrative sex with a man }\end{array}$ & $46(24.2)$ & $15(9.8)$ & $61(17.5)^{\star \star}$ & $4(1.2)^{\star *}$ & $66(9.3)$ \\
\hline $\begin{array}{l}\text { Excluded because of other } \\
\text { sexual contact with a man }\end{array}$ & $36(19.0)$ & $13(8.5)$ & $49(14.1)^{\star \star}$ & $2(0.6)^{\star *}$ & $51(7.2)$ \\
\hline Excluded for other reasons & $12(6.3)$ & $9(5.9)$ & $23(6.6)$ & $36(10.3)$ & $59(8.4)$ \\
\hline $\begin{array}{l}\text { Medical reasons (such as } \\
\text { anaemia) }\end{array}$ & $12(6.3)$ & $15(9.8)$ & $27(7.8)$ & $34(9.7)$ & $61(8.6)$ \\
\hline Never considered it & $26(13.4)$ & $38(24.8)$ & $64(18.4) \S \S$ & $88(25.2) \S \S$ & $157(22.2)$ \\
\hline Do not want to & $23(12.1)$ & $10(6.5)$ & $33(9.5)$ & $43(12.3)$ & $78(11.0)$ \\
\hline $\begin{array}{l}\text { Considered it but not got around } \\
\text { to it }\end{array}$ & $21(11.1)$ & $26(17.0)$ & $49(14.1)^{\star *}$ & $83(23.8)^{\star *}$ & $133(18.8)$ \\
\hline Too busy & $12(6.3)$ & $16(10.5)$ & $29(8.3)$ & $41(11.8)$ & $70(9.9)$ \\
\hline Fear of needles or pain & $18(9.5)$ & $25(16.3)$ & $43(12.4)$ & $38(10.9)$ & $81(11.5)$ \\
\hline
\end{tabular}

*MSM donor deferral=UK blood services' lifetime ban on donation by men who had ever had penetrative sex with a man (enacted 1986). †Includes non-response with regard to how recent the experience of male penetrative sex was. fIncludes non-response with regard to experience of penetrative sex with men. §Includes England, Scotland, and Wales.

IEver donated blood since first penetrative sex with male and since MSM donor deferral (1986 or later). Cases in which neither reported nor calculated compliance could be established $(n=27)$ were excluded from all compliance related analyses.

${ }^{* *} \mathrm{P}<0.01$ (comparing experience of penetrative sex or date of such sex for ineligible donation).

††Numerators are an estimate reported to the nearest integer assuming that (a) $67 \%$ of donations in 2008 were made between May and December and (b) on average, 50\% of these donations were made within 12 months of participation in the survey (May to December 2009). Blood donation during the past 12 months was calculated as ((No of men who last donated in 2009) + (No of men who last donated in $2008 \times 0.67 \times 0.5)$ ) / No of respondents.

$\ddagger \ddagger$ Multiple response, so the cumulative percentages may not equal and may exceed 100 . Denominator, however, is constant across response options as non-response applied to the entire question.

$\S \S \mathrm{P}<0.05$ (comparing experience of penetrative sex or date of such sex for ineligible donation). 
Table 4| Perceptions of men reporting any male sexual contact on current and potential revisions to MSM donor deferral ${ }^{\star}$ criteria. Values are numbers (percentages) of respondents in agreement with statements $\dagger$

\begin{tabular}{|c|c|c|c|c|}
\hline \multirow{2}{*}{$\begin{array}{l}\text { Perceptions of current donor deferral criteria } \\
\text { and screening procedures }\end{array}$} & \multicolumn{2}{|c|}{ Men with experience of penetrative male sex } & \multirow{2}{*}{$\begin{array}{l}\text { Men with experience of } \\
\text { non-penetrative male } \\
\text { sex only }\end{array}$} & \multirow[b]{2}{*}{ All¥ } \\
\hline & "Non-compliers"* & "Compliers"* & & \\
\hline $\begin{array}{l}\text { The rules around who can give blood are clear and } \\
\text { easy to understand }\end{array}$ & $24 / 50(48)$ & $177 / 419(42)$ & 229/511 (45) & $440 / 1009(43.6)$ \\
\hline $\begin{array}{l}\text { The rule that excludes men who have sex with men } \\
\text { for life should stay that way because we need to } \\
\text { make the sure the blood supply is completely safe }\end{array}$ & $17 / 50(34)$ & $130 / 420(31)$ & $258 / 514(50)$ & $414 / 1012(40.9)$ \\
\hline $\begin{array}{l}\text { The blood service needs to provide more information } \\
\text { and explanation about who can and can't give blood }\end{array}$ & $36 / 50(72)$ & $326 / 421(77)$ & $356 / 514(69)$ & $740 / 1014(73.0)$ \\
\hline $\begin{array}{l}\text { Because blood donations are screened, I believe it's } \\
\text { safe for me to give blood, and I would do so } \\
\text { regardless of the rules }\end{array}$ & $25 / 49(51)$ & $197 / 420(47)$ & $257 / 511(50)$ & $489 / 1008(48.5)$ \\
\hline \multicolumn{5}{|l|}{$\begin{array}{l}\text { Likely conduct if MSM donor deferral criterion } \\
\text { changed: }\end{array}$} \\
\hline $\begin{array}{l}\text { A change in the rule would make no difference to } \\
\text { whether I give blood }\end{array}$ & $26 / 50(52)$ & $195 / 419(47)$ & $300 / 513(58)$ & $535 / 1010(53.0)$ \\
\hline $\begin{array}{l}\text { l'd be more likely to give blood because the rule } \\
\text { that men who have sex with men can never give } \\
\text { blood has put me off in the past }\end{array}$ & $18 / 50(36)$ & $194 / 416(47)$ & $95 / 509(19)$ & $314 / 1000(31.4)$ \\
\hline $\begin{array}{l}\text { I would be more likely to give blood because the } \\
\text { new rule would make me eligible to donate }\end{array}$ & $17 / 50(34) \S$ & $210 / 418(50) \S$ & $121 / 513(24)$ & $357 / 1008(35.4)$ \\
\hline $\begin{array}{l}\text { Groups perceived to be excluded from blood donation } \\
\text { under current criteriaף }\end{array}$ & $(n=50)^{\star *}$ & $(n=424)^{\star *}$ & $(\mathrm{n}=522)$ & $(\mathrm{n}=1028)^{\star \star}$ \\
\hline Men who have ever had penetrative sex with a man & $13(26)$ & $127(30)$ & $110(21)$ & $258(25.1)$ \\
\hline $\begin{array}{l}\text { Men who have ever had unprotected penetrative } \\
\text { sex with a man }\end{array}$ & $19(38)$ & $148(35)$ & $152(29)$ & $326(31.7)$ \\
\hline $\begin{array}{l}\text { Men who have ever had any sexual contact with a } \\
\text { man }\end{array}$ & $17(34)$ & $170(40)$ & $112(21)$ & $309(30.1)$ \\
\hline Anyone who has ever sold sex & $20(40)$ & $127(30)$ & $144(28)$ & $298(29.0)$ \\
\hline $\begin{array}{l}\text { Anyone who has ever injected drugs for non-medical } \\
\text { purposes }\end{array}$ & $22(44)$ & $184(43)$ & 227 (43) & $443(43.1)$ \\
\hline Don't know & $12(24)$ & $97(23)$ & $150(29)$ & $270(26.3)$ \\
\hline
\end{tabular}

"MSM donor deferral=UK blood services' lifetime ban on donation by men who had ever had penetrative sex with a man (enacted 1985). "Non-compliers" and "compliers" refer to such men's compliance with the lifetime ban.

†Includes responses "strongly agree" and "tend to agree" (attitudinal questions used a 5 point Likert scale). Denominators exclude non-response.

fIncludes non-response regarding history of male penetrative sex and blood donation history.

$\S$ Significant at $\mathrm{P}<0.05$ (comparing responses of "non-compliers" and "compliers").

IMultiple response, so the cumulative percentages may not equal and may exceed 100. Denominator, however, is constant across response options as non-response applied to the entire question.

${ }^{*}$ Denominator is specified total; excludes non-response. 


\section{Figure}

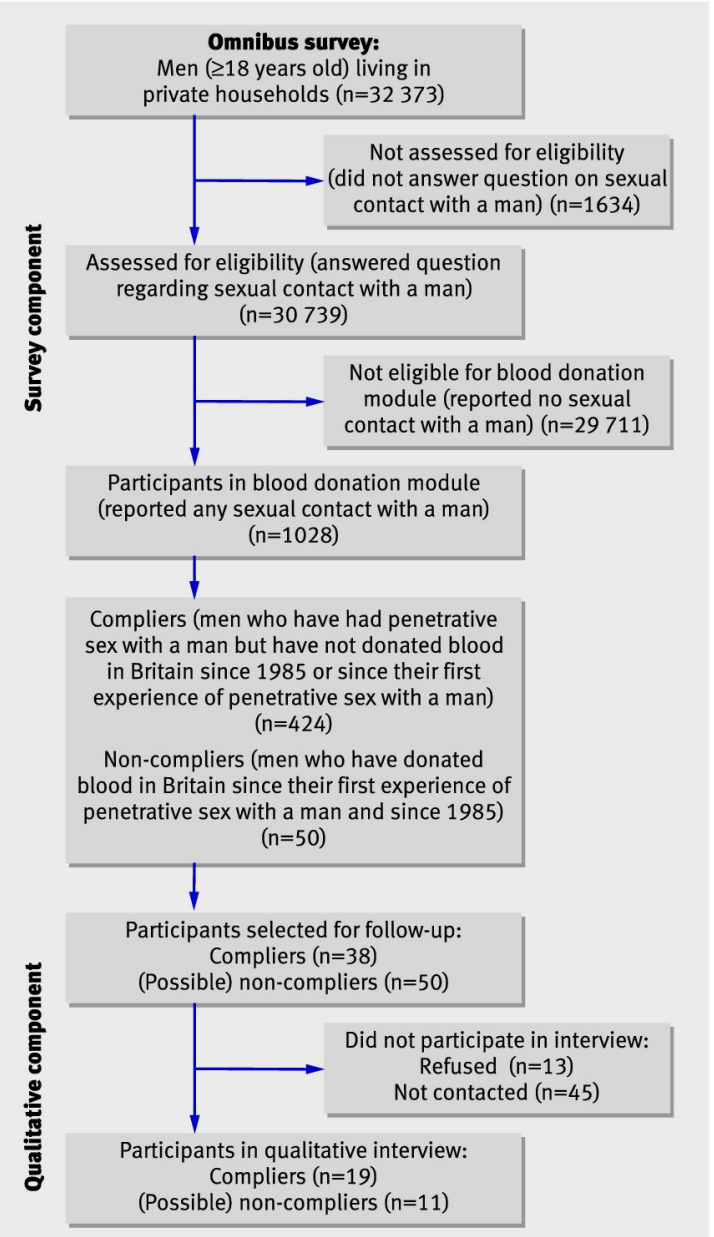

Recruitment of participants into the survey and qualitative interview 